\title{
GCS score and MRI grading does not predicts the outcome in dai patients - a prospective study
}

\author{
Ketan Hedaoo $^{1}$, Vikas Rajpurohit ${ }^{2}$, Sunil Garg ${ }^{1}$, Sharad Thanvi ${ }^{1}$, \\ Vallabh B Nagocha ${ }^{1}$ \\ ${ }^{1}$ Neurosurgery Department; ${ }^{2}$ Anesthesia Department \\ S.N. Medical College, Rajasthan University of Health Science, Jodhpur, Rajasthan, INDIA
}

\begin{abstract}
Diffuse axonal injury (DAI) is a type of brain injury due to extensive lesions in white matter tract occurring over a wide area. It is one of the most common and devastating types of traumatic brain injury and major cause of unconsciousness and persistent vegetative state after head trauma. DAI occurs in about half of all cases of severe head trauma. The study was undertaken to correlate the GCS at time of admission and Grade of DAI with the outcome. Aim: - To correlate GCS Score and MRI grading with the outcome in DAI patients. Setting and Design: - A 3 months prospective study was conducted in Department of Neurosurgery. Material and Method: - Sources of Data: - Patients admitted with clinical diagnosis of Diffuse Axonal Injury under Department of Neurosurgery. Sample size: - 50 cases of Diffuse Axonal Injury. Inclusion Criteria: - All traumatic DAI Patients requiring ICU care. Exclusion Criteria: - Head injury patients requiring Surgery. Patients other findings on imaging as contusion, EDH, SDH, IVH.Patients with Sepsis. Patients with other co morbid Illness as DM, Hypertension. Patients who were haemodynamically unstable at the time of admission. Patients with other systemic injuries. Statistical Analysis. Data so collected was analysed using IBM SPSS Statistics Windows, version 20.0 (Armonk, NY: IBM Corp) for the generation of descriptive and inferential statistics. The statistical significant difference among age groups was determined by Chi square test and one way analyses of variance. The level of significance was set at $\mathrm{p}<0.05$. Results: Distribution of patients according to Gender and MRI Grading shown in Table 1. Total 50 patients were evaluated out of which 38 (76\%) were male and $12(24 \%)$ were female. Number of patients according to Grading [Table 2 and Fig. 1] Out of 50 patients admitted 10\% (5) constitutes Grade 1 DAI, 28\% (14) grade II, and 62\% (31) Grade III. Grades of DAI according to age of patients [Table 3]. Mean age in Grade I patients was
\end{abstract}


20.83 \pm 3.63 , Grade II 23.36 \pm 7.089 and in Grade III 22.32 \pm 11.38 . Comparisons of Mean ICU stay Mean Hospital stay and Mortality in Different GCS Groups [Table 4]. In patients with GCS 3-8 the mean ICU stay was $18.48 \pm 14.53$, mean hospital stay was $37.24 \pm 12.31$ and Mortality was $15.21 \%$, in patients with GCS 9-12, mean ICU stay was $10.5 \pm 4.12$, Hospital stay $19.4 \pm 5.79$ and mortality was $25 \%$. Comparison of Mean ICU stay, and Ventilator stay in different MRI Grade [Table 5]. In patients with Grade I DAI Mean ICU stay was $17.13 \pm 14.65$ and Mean Ventilator stay was $6.24 \pm 2.57$, In Grade II DAI mean ICU stay was $20.57 \pm 15.45$ and Ventilator stay was $12.01 \pm 3.82$ and in Grade III mean ICU stay was $23.4 \pm 15.41$ and mean Ventilator stay was $10.89 \pm 2.58$. Mortality of patients in different Grades and GCS groups [Table 6 and Fig 2] In patients with GCS 9-12 and Grade III only 1 patient died, while in patients with GCS 38 total 7 died, 2 in Grade I, 2 in Grade II and 3 in Grade III. Complications [Table 7] Out of 5 patients in Grade I, electrolyte imbalance was seen in 1 patient in the form of hypernatraemia, 1 patient developed seizure, and septicaemia was seen in 1 and 1 patient developed shock. In patients with Grade II DAI out of 14 patients 1 had ventilator associated pneumonia, hypernatraemia was seen in 1, 1patient developed bed sore, seizures seen in 3, 2 had septicaemia \& shock was seen in 2, and in 1 drug reaction occurred. Out of 31 patients with Grade III DAI 2 developed ventilator associated pneumonia, hypernatraemia and hyponatraemia was seen in $2 \& 1$ patient respectively, 2 developed bedsore, seizure in 1 and septicaemia and shock was seen in 3-3 patients. Conclusion:-Diffuse axonal injury is a very common finding in traumatic head injury patients. Magnetic resonance imaging and GCS scoring does not have appropriate prognostic value in pure DAI patients and a better survival rate can be achieved with dedicated neurocritical care and neurosurgical management

Key words: DAI, ICU Stay, GCS, MRI.

\section{Introduction}

Head injury includes injury to brain and other parts of head as scalp, skull and can be of open or closed types. Closed head injuries causes two major types of traumatic brain injury - Focal brain injury and Diffuse axonal injury. In focal brain injury, Orbitofrontal cortex, ventromedial prefrontal cortex and temporal pole are frequently damage because of shape of skull base. [1] DAI is one of the most common pathology of traumatic brain injury, occurring in both mild and severe cases and is one of the major causes of traumatic brain injury leading to coma. [2] It occurs most often in RTA, fall or assaults in which strong inertial force causes axons to loose their normal elasticity and become brittle. [3] DAI occurs in $40-50 \%$ of traumatic brain Injury. [4] 
In DAI, subcortical neuronal damage results from stretching and shearing of axons as brain moves inside skull. Histopathologically DAI is characterized by Wallerian type axonal degeneration in parasagittal white matter, corpus callosum and dorsal upper brainstem due to shearing forces by acceleration, deceleration or rotation of brain. [5] In DAI brain damage was thought to occur diffusely in white matter [6] while the effect on Grey matter or whole brain is poorly understood. Diffuse degeneration of cerebral white matter was first defined by Strich in a study of patients with severe post- traumatic dementia in 1956. [7] The time course of pathological changes were established by Adams et al. [8] Diffuse axonal injury can be diagnosed using clinical signs and radiological evidence. Brain Magnetic Resonance Imaging (MRI) is the most sensitive method to diagnose diffuse axonal injury, especially in gradient echo image. $[9,10,11]$

\section{Method of Collection of data}

After taking detailed history all patients were examined and investigated. Severity of head injury was assessed via modified Glasgow Coma Score and MRI brain. According to GCS head injury is classified as mild having GCS 14-15, moderate 9-13, and severe with GCS less than 8 . We divided patients into three groups according to grade of MRI finding according to classification proposed by Adams.
Grade 1. Involves grey-white matter interface, most commonly parasagittal regions of frontal lobes, periventricular temporal lobes, less commonly: parietal and occipital lobes, internal and external capsules and cerebellum.

Grade 2. Involves corpus callosum in addition to stage 1 locations, most commonly: posterior body and splenium but does advance anteriorly with increasing severity of injury

Grade 3. Involves brainstem in addition to stage 1 and 2 locations most commonly: rostral midbrain, superior cerebellar peduncles, medial lemniscus, and corticospinal tracts.

Table 1

\begin{tabular}{|c|l|l|l|l|}
\hline $\begin{array}{c}\text { MRI } \\
\text { grading }\end{array}$ & \multicolumn{1}{|c|}{ Male } & \multicolumn{1}{|c|}{ Female } & $\begin{array}{c}\text { Chi } \\
\text { square }\end{array}$ & P-Value \\
\hline Grade 1 & $5(10 \%)$ & - & & \\
\hline Grade 2 & $11(22 \%)$ & $3(6 \%)$ & 0.57 & 0.751 \\
\hline Grade 3 & $22(44 \%)$ & $9(18 \%)$ & & \\
\hline
\end{tabular}

Table 2

\begin{tabular}{|l|l|}
\hline Grade I & $10 \%$ (5 patients) \\
\hline Grade II & $28 \%$ (14 Patients) \\
\hline Grade III & $62 \%$ (31 Patients) \\
\hline
\end{tabular}

Table 3

\begin{tabular}{|l|l|l|l|}
\hline \multicolumn{1}{|c|}{$\begin{array}{c}\text { MRI } \\
\text { Grading }\end{array}$} & $\begin{array}{c}\text { Age Group (Mean } \\
+ \text { SD) }\end{array}$ & $\begin{array}{c}\text { Anova } \\
\text { test }\end{array}$ & P-Value \\
\hline Grade I & $20.83 \pm 3.63$ & & \\
\hline Grade II & $23.36 \pm 7.089$ & 0.1317 & 0.8769 \\
\hline Grade III & $22.32 \pm 11.38$ & & \\
\hline
\end{tabular}


Table 4

\begin{tabular}{|l|l|l|l|}
\hline \multicolumn{1}{|c|}{$\begin{array}{c}\text { GCS } \\
\text { Groups }\end{array}$} & \multicolumn{1}{|c|}{ ICU stay } & Hospital stay & Mortality \\
\hline $3-8$ & $18.48 \pm 14.53$ & $37.24 \pm 12.31$ & $7(15.21 \%)$ \\
\hline $9-12$ & $10.5 \pm 4.12$ & $19.4 \pm 5.79$ & $1(25 \%)$ \\
\hline $\begin{array}{l}\text { Anova, } \\
\text { P-Value }\end{array}$ & $1.17,0.283$ & $8.12,0.006$ & \\
\hline
\end{tabular}

Table 5

\begin{tabular}{|l|l|l|}
\hline MRI Grading & $\begin{array}{l}\text { ICU } \\
\text { stay }(\text { mean } \pm \text { SD })\end{array}$ & $\begin{array}{l}\text { Ventilator } \\
\text { stay(Mean } \\
\pm \text { SD })\end{array}$ \\
\hline Grade I & $17.13 \pm 14.65$ & $6.24 \pm 2.57$ \\
\hline Grade II & $20.57 \pm 15.45$ & $12.01 \pm 3.82$ \\
\hline Grade III & $23.4 \pm 15.41$ & $10.89 \pm 2.58$ \\
\hline $\begin{array}{l}\text { Anova test,P- } \\
\text { Value }\end{array}$ & $0.4408,0.6461$ & $<0.01$ \\
\hline
\end{tabular}

Table 6

\begin{tabular}{|l|l|l|l|l|}
\hline $\begin{array}{l}\text { MRI } \\
\text { grading }\end{array}$ & GCS & Mortality & GCS & Mortality \\
\hline Grade I & $9-12$ & - & $3-8(5)$ & 2 \\
\hline Grade II & $9-12(2)$ & - & $3-8(12)$ & 2 \\
\hline Grade III & $9-12(2)$ & 1 & $3-8(29)$ & 3 \\
\hline
\end{tabular}

Table 7

\begin{tabular}{|c|c|c|c|c|c|c|c|c|}
\hline 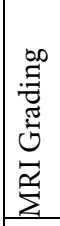 & 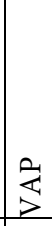 & 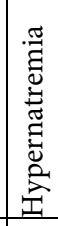 & 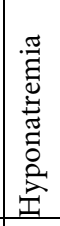 & 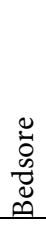 & 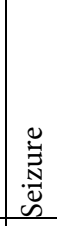 & 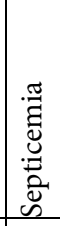 & $\begin{array}{l}\frac{y}{4} \\
0 \\
\text { w } \\
\end{array}$ & 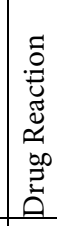 \\
\hline $\mathrm{I}$ & - & 1 & - & 1 & 1 & 1 & 1 & - \\
\hline II & 1 & 1 & - & 1 & 3 & 2 & 2 & 1 \\
\hline III & 2 & 2 & 1 & 2 & 1 & 3 & 3 & - \\
\hline
\end{tabular}

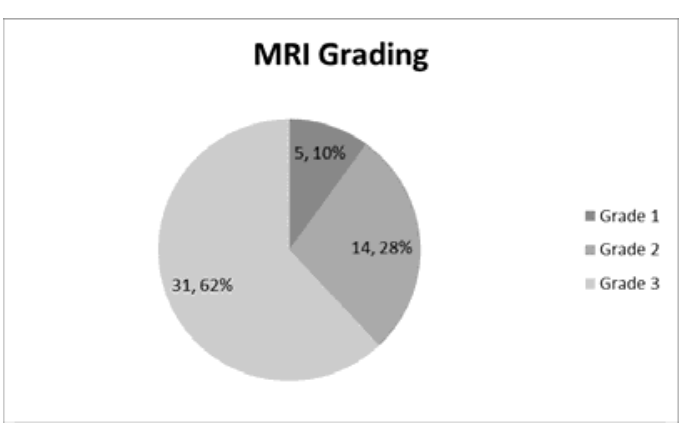

Figure 1

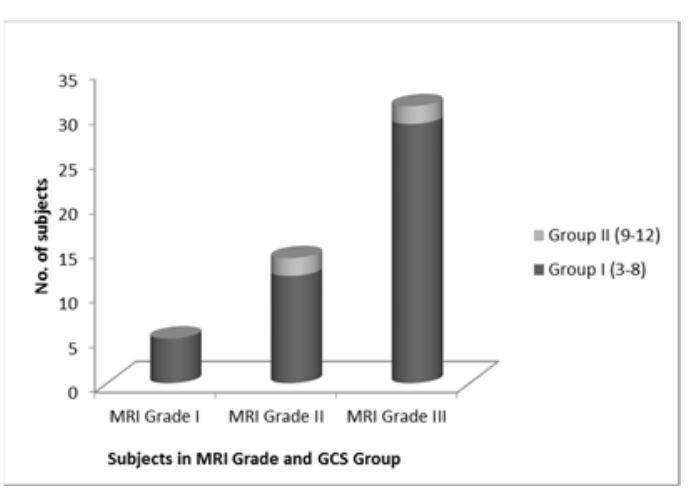

Figure 2 

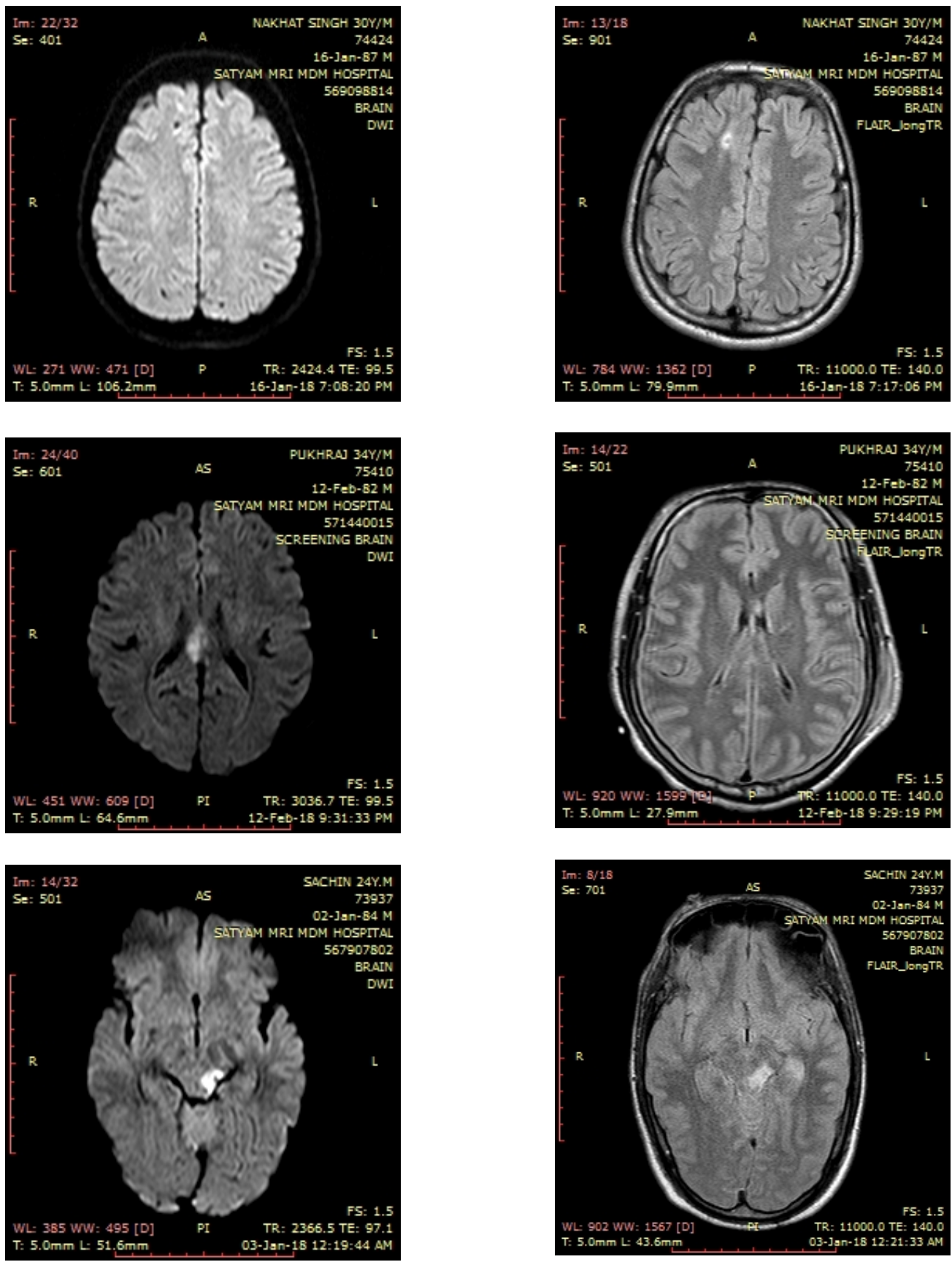

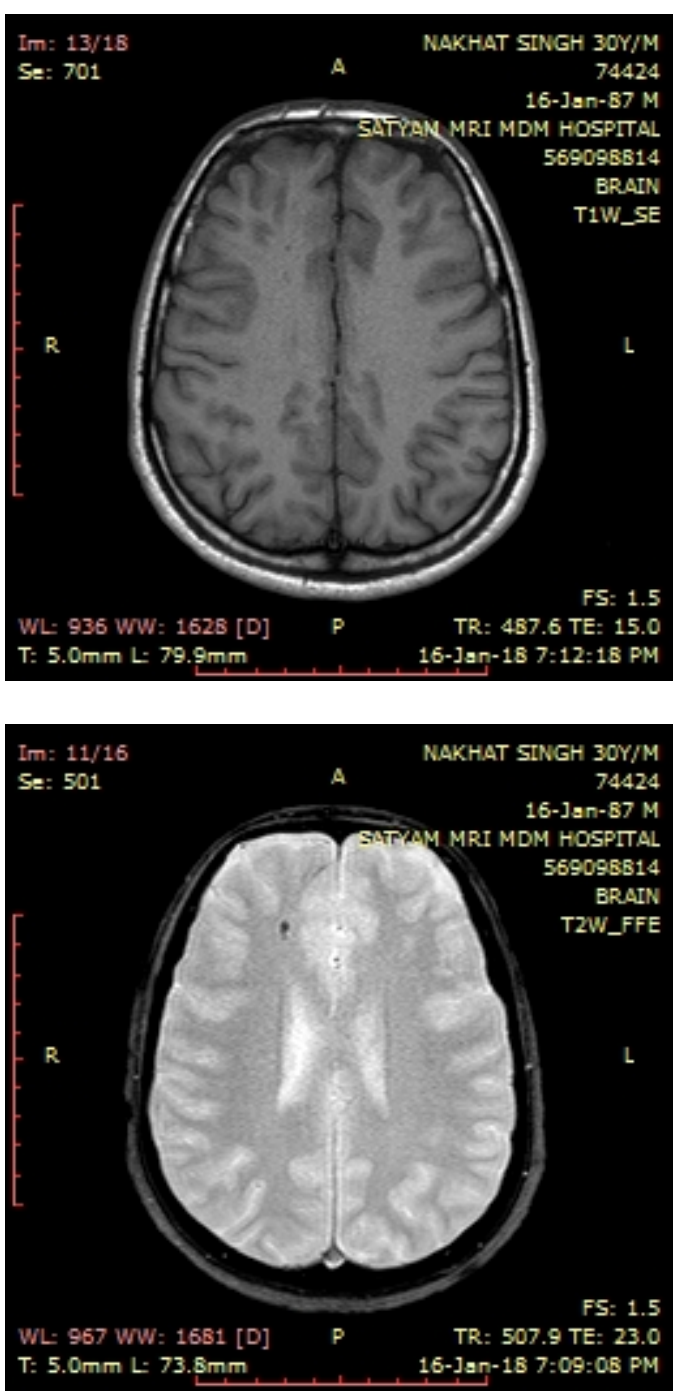

\section{Discussion}

Diffuse axonal injury (i.e., widespread damage to axons in white matter of brain) is well recognized severe posttraumatic head injury. [12] It is defined as prolonged post traumatic coma following injury without demonstrable intracranial mass lesion. [13, 14, 15] In 1956, Strich [7] defined the "diffuse degeneration of cerebral white matter" in a series of patients with severe post-traumatic dementia diffuse axonal injury is caused by acceleration-deceleration effects of mechanical input to head on shaking of brain within skull.[14,15] This results in shearing or stretching of nerve fibres with consequential axonal damage. Mostly, this injury mechanism is caused by traffic accidents producing comparatively prolonged acceleration and is dependent on Direction, Magnitude and speed of head motion during injury. Diffuse axonal injury readily occurs in coronal acceleration of head and occasionally in sagittal or oblique direction. [16] In mild head injury lesions are localized to frontotemporal cerebral white matter and stronger rotatory acceleration causes additional lesions in corpus callosum and brain stem. Gannarelli et al [16] reported severe head injury has a tendency to cause deeper lesions. Adam et al established pathological changes in due time course [8].In humans, instantaneous injury occurs to numerous axons in white matter of brain manifested by axonal retraction balls visible on microscopic examination. Gross lesion associated with severe diffuse axonal injury in humans consist of haemorrhagic tears in corpus callosum and dorsolateral quadrant or rostral brain stem. Several days later, microglial clusters appear and axonal retraction balls start to disappear. Months later bulk of white matter is reduced and and long tract degeneration is seen. [16]

Diffuse axonal injury can be diagnosed clinically (level of consciousness and neurological deficits) and radiological findings. Zimmerman[17] reported first study 
of radiological diagnosis of diffuse axonal injury that includes small hemorrhagic lesion on corpus callosum, upper brainstem, corticomedullary junction, parasagittal area and basal Ganglia .Brain computed Tomography findings lack accuracy in prediction of patients outcome and do not correspond well to patient's GCS score or neurological state[10,18].

Brain MRI gradient echo imaging is far more sensitive than spin echo imaging on paramagnetic lesion such as hemorrhage or calcification for a long time, and is considered most sensitive for conforming presence of small hemorrhagic lesion in white matter, corpus callosum, and brain stem in diffuse axonal injury.[9,10,11]

As the studies done by Gannarelli.T.A et al, R.kalff et al, and Levati et al shows that patients presenting with low GCS have poorer outcome but in our study in patients with GCS less than 8 the mortality was only $15 \%$ (7 out of 46) and in patients with GCS more than 8 the mortality was $25 \%$ ( 1 out of 4 ).

Oh.et.al and Kim et al reported worse outcome in patients with Grade II and III DAI, but in our study in patients with Grade I DAI mortality was 40\% (2 out of 5 ) in Grade II DAI mortality was $14.21 \%$ (2 out of 14 ) and in patients with Grade III DAI mortality was $12.9 \%$ (4 out of 31) Better outcome seen our study can be due to early referral of patients, better neurocritical care, early tracheostomy, early recognition of complications and its management.

\section{Correspondence}

Ketan Hedaoo

Postal Address of Corresponding Author: Room no 110, PG hostel; Mathuradas Mathur hospital, Department of neurosurgery, Dr. S.N. Medical College, Jodhpur - 342001, Rajasthan, India

\section{References}

1. Adams JH, Graham DI, Scott G.et al .Brain damage in fatal non missile head injury. Journal of clinical pathology 1980; 33: 1132-1145.

2. Smith D., Meaney D., \& Shull W. Diffuse Axonal Injury in Head Trauma .J Head Trauma Rehabil.2003;18:4.

3. Wang H., Ma Y. Experimental Models of Traumatic axonal injury. Journal of clinical Neuroscience.2010; 172.

4. Thomas M. \& Dufour L. Challenges of Diffuse axonal injury diagnosis. Rehabil Nurs.2009; 34(5): 179-80.

5. Meythaler JM, Peduzzi JD, Eleftheriou E, et al. Current concepts: Diffuse axonal injury-associated traumatic brain injury. Archives of Physical Medicine and Rehabilitation 2001; 82: 1461-1471.

6. Gentry LR, Godersky JC, Thompson B et al.Prospective comparative study of intermediate-field $M R$ and CT in evaluation of closed head trauma .American journal or roentgenology: 1988; 150, 673-682. 7. Strich SJ. Diffuse degeneration of the cerebral white matter in severe dementia following head injury. J Neurol Neurosurg Psychiatry.1956;19:163-185.

8. Adams H, Mitchell DE, Graham DI, Doyle D. Diffuse brain damage of immediate impact type. Its relationship to "Primary brain stem damage" in head injury. Brain.1977; 100:489-502.

9. Kim $\mathrm{CH}$, Lee HK, Koh YC, Hwang DY .Clinical analysis of Diffuse axonal injury (DAI) diagnosed with magnetic resonance image (MRI) J Korean Neurosurg Soc. 1997;26:241-248.

10. Kim HJ, Park IS, Kim JH, Kim KJ, Hwang SH, Kim ES, et al. Clinical analysis of the prognosis of the patients with cerebral diffuse axonal injuries, based on gradientecho MR imaging. J Korean Neurosurg Soc.2001;30:168172.

11. Oh KS ,Ha SI ,Suh BS, Lee HS, Lee JS. The correlation of MRI findings to outcome in diffuse axonal 
injury patients. J Korean Neurosurg Soc. 2001; 30(SupplI): S20-S24.

12. Adams JH, Graham DI, Murray LS, Scott G. Diffuse axonal injury due to nonmissile head injury in humans: an analysis of 45 cases. Ann Neurol. 1982; 12:557-563.

13. Alberico AM, Ward JD, Choi SC, Marmarou A, Young HF.Outcome after severe head injury: relationship to mass lesion, diffuse injury, and ICP course in paediatric and adult patients. J Neurosurg.1987; 67:648-656.

14. Eisenberg HM, Gary HE, Jr, Aldrich EF, Saydjari C, Turner B, Foulkes MA, et al .Initial CT findings in 753 patients with severe head injury .A report from NIH Traumatic Coma Data Bank. J Neurosurg.1990;73:688698.

15. Eum SW, Lim DJ, Kim BR, Cho TH, Park JY, Suh JK, et al .Prognostic Factors in patients with diffuse axonal injury. J Korean Neurosurg Soc. 1998; 27:16681674.

16. Gannarelli T., Thibault L., Adams J., Graham D., Thompson C., \& Marcincin R., Diffuse axonal injury and traumatic coma in the primate .Ann Neurol.1982;12:564-574.

17. Zimmerman RA, Bilaniuk LT, Ganneralli $\mathrm{T}$. Computed tomography of shearing injuries of cerebral white matter .Radiology. 1978; 127:393-396.

18. Zimmerman RA, Bilanuik LT, Hackney DB. Goldberg HI , Grossman RI. Head injury: early results of comparing CT and high field MR . AJR Am J Roentgenol. 1986; 147:1215-1222.

19. Ganneralli TA, Spielman GM, Langfitt TW, Gildenberg PL, Harrington T, Jane JA, et al Influence of the type of Intracranial lesion on outcome from severe head injury. J Neurosurg. 1982;56:26-32.

20. Kalff R, Kocks W, Pospiech J, Grote W. Clinical outcome after head injury in children. Childs Nerv Syst. 1989; 5:156-159.

21. Laveti A, Farina ML, Vecchi G, Rossanda M, Marrubini MB. Prognosis of severe head injuries. J Neurosurg . 1982;57:779-783. 